\title{
EU QUERO É “BOTAR” O MEU BLOCO NA RUA: UMA ANÁLISE DO CARNAVAL DE BELO HORIZONTE ENTRE OS ANOS DE 2013 E 2015
}

WHAT I WANT IS TO PUT MY CARNIVAL GROUP ON THE STREET: AN ANALYSIS OF THE BELO HORIZONTE CARNIVAL FROM 2013 TO 2015

LO QUE YO QUIERO ES DESFILAR CON MI BLOQUE POR LA CALLE: UN ANÁLISIS DEL CARNAVAL DE BELO HORIZONTE ENTRE LOS AÑOS 2013 Y 2015

\section{Geórgia Caetano de Oliveira Santos}

Faculdade Novos Horizontes

Mestre em Administração e Graduação em Jornalismo

georgiacaetano@hotmail.com

\section{Caissa Veloso e Sousa}

Faculdade Novos Horizontes

Doutora e Mestre em Administração com graduação em Ciências Econômicas

caissaveloso@yahoo.com.br

\section{Jefferson Rodrigues Pereira}

Faculdade Novos Horizontes

jeffersonrodrigues@live.com

Mestrado e Graduação em Administração

Data de Submissão: 16/07/2015

Data de Aprovação: 01/03/2016 
RESUMO: Este trabalho objetiva discutir o Carnaval de Belo Horizonte entre os anos de 2013 e 2015. Com o crescimento das manifestações culturais de rua, a capital mineira vem experimentando nos últimos anos o renascimento da festa em todas as suas regiões. $O$ envolvimento de agentes como poder público municipal, patrocinadores e carnavalescos fez-se necessário para o fornecimento de infraestrutura urbana, logística e da agenda de entretenimento. Destaca-se que o público do evento tem aumentado anualmente, movimentando a economia da cidade. $O$ crescimento recente do Carnaval de Belo Horizonte é tema pouco explorado no meio acadêmico, o que o torna interessante como objeto de estudo. Esta pesquisa utilizou uma abordagem qualitativa, por meio de análise documental e descritiva dos principais resultados da festa. Para analisar a evolução do Carnaval na cidade, este trabalho se amparou nos relatórios de atividades da Empresa Municipal de Turismo de Belo Horizonte, que organiza o evento, e nas notícias veiculadas nos jornais Estado de Minas, o Tempo e Hoje em Dia, durante a realização da festa. Conclui-se com este estudo que o Carnaval evoluiu em organização, número de público, ganhou investimentos privados e passou a ser considerado como o maior evento turístico realizado na capital mineira.

PALAVRAS CHAVE: Carnaval. Evento. Turismo.

ABSTRACT: This paper discusses the Belo Horizonte Carnival between 2013 and 2015. With the growth of cultural street manifestations, the state capital has been seeing a resurgence of the festival in recent years, in all its regions. The involvement of agents such as municipal government, sponsors, and carnival goers is necessary for the provision of urban infrastructure, logistics and the entertainment program. It is noteworthy that the public of the event has increased annually, boosting the city's economy. The recent growth of Belo Horizonte's Carnival is a subject that has been little explored in academic circles, therefore it is an interesting object of study. This research uses a qualitative approach, through documentary and descriptive analysis of the main outcomes of the festival. To analyze the evolution of the carnival in the city, this study is supported by the reports of activities of the Empresa Municipal de Turismo de Belo Horizonte (Municipal Tourism Company of Belo Horizonte - free translation), which organizes the event, and news published in the newspapers Estado de Minas, Tempo, and Hoje em Dia, during the Carnival. Based on this study, it is concluded that the Carnival has evolved in terms of organization, numbers of attendees, and gains in private investments, and it is now considered the biggest tourism event in Belo Horizonte.

KEYWORDS: Carnival. Event. Tourism.

RESUMEN: Este trabajo tiene el objetivo de analizar el Carnaval de Belo Horizonte entre los años 2013 y 2015. Con el crecimiento de las manifestaciones culturales callejeras, la capital de Minas Gerais viene experimentando en los últimos años un renacimiento de la fiesta en todas sus regiones. Se hizo necesaria la participación de agentes como el poder público municipal, patrocinadores y carnavalescos para proporcionar la infraestructura urbana, logística y la agenda de la fiesta. Cabe destacar que el público del evento viene aumentando anualmente, dinamizando la economía de la ciudad. El crecimiento reciente del Carnaval de Belo Horizonte es un tema poco explotado en el medio académico, lo que lo vuelve interesante como objeto de estudio. Esta investigación utilizó un abordaje cualitativo, por medio de análisis documental y descriptivo de los principales resultados de la fiesta. Para analizar la evolución del Carnaval en la ciudad, este trabajo se fundamentó en los informes de actividades de la Empresa Municipal de Turismo de Belo Horizonte, que organiza el evento, y en las noticias difundidas en los periódicos Estado de Minas, O Tempo y Hoje em Dia, durante la realización de la festividad. Se concluye con este estudio que el Carnaval evolucionó en organización, número de público, recibió inversiones privadas y pasó a ser considerado como el mayor evento turístico realizado en la capital de Minas Gerais.

PALABRAS CLAVE: Carnaval. Evento. Turismo. 


\section{INTRODUÇÃO}

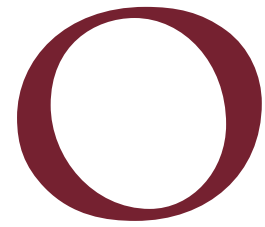

Carnaval é a uma tradição cultural brasileira que foi transformada em referência mundial, quando se analisa o conjunto das festas populares no país. Durante a festa, o cotidiano da população ganha nova ordem e, nos locais no país onde a folia é pública, as ruas ganham uma diferente forma de ocupação, mais anárquica e cheia de cores, divertimento e brincadeiras (TEIXEIRA, 2005).

Teixeira (2005) salienta que, durante o Carnaval, o uso de fantasias e máscaras permite viver um momento que quebra a realidade cotidiana, possibilitando a transgressão dos papéis sociais e, ainda, facilita a expressão crítica da política com manifestações satíricas ao poder político e econômico. O que se pretende durante a festa é "a ruptura da ordem social, a inversão de valores e de papeis para dar lugar a um espelho invertido que é socialmente estabelecido" (TEIXEIRA 2005, p.17).

Pereira Filho (2006), em seu trabalho "Glórias conquistas perdas e disputas: as muitas máscaras dos carnavais de rua em Belo Horizonte", destaca que o Carnaval é uma festa singular, que exacerba ainda mais os conflitos cotidianos. A festa pode ser identificada também como "um palco simbólico onde os interesses e desejos dos diferentes grupos sociais marcam uma presença substancial" (PEREIRA FILHO, 2006, p.66). Em complemento, Santos (2008) ressalta que o Carnaval chama a atenção em diversos aspectos, por se tratar de oportunidade para resgatar tradições, preservar a cultura local e reafirmar os estreitos laços de amizade entre as comunidades que participam do evento, sendo, ainda, fonte de trabalho e de renda.

Pereira Filho (2006) afirma que a festa faz uma boa combinação de bom humor com sátira ao cotidiano, permitindo que sujeitos anônimos empreendam uma busca pelos direitos à cidadania cultural. Em Belo Horizonte, segundo o autor, o Carnaval surgiu nas primeiras décadas do século XX como alternativa de inserção social para as camadas da sociedade que se sentiam excluídas no processo de modernização da nova capital. 
A análise histórica da relação entre as festas carnavalescas e os governos mostra que, na maioria das vezes, a Administração Pública e o Carnaval sempre estiveram ligados, em relações que por vezes eram consensuais ou, em circunstâncias diferentes, conflituosas (SANTOS, 2008). Ainda segundo o autor, normalmente, a estrutura responsável pela organização do Carnaval, dentro da Administração Pública, fica alojada nas áreas de cultura ou turismo. Na cidade de Belo Horizonte, capital do estado de Minas Gerais, a programação oficial do Carnaval é gerida pela Empresa Municipal de Turismo (Belotur), um órgão público vinculado à Prefeitura de Belo Horizonte. O evento conta ainda com suporte oficial de outros nove órgãos do município, assim como previsto na Portaria Conjunta n 001/2014, que instituiu a Comissão Especial responsável pela organização e pelo planejamento das ações relacionadas ao Carnaval do ano de 2014. Integram a Comissão: a Procuradoria Geral do Município; a Empresa de Transporte e Trânsito de Belo Horizonte; a Guarda Municipal de Belo Horizonte; as Secretarias Municipais de Governo, de Saúde, de Administração Regional Municipal Centro-Sul, de Serviços Urbanos, de Limpeza Urbana; a Procuradoria Geral; e a Assessoria de Comunicação Social do Município.

Especificamente nos últimos três anos (2013 a 2015), o crescimento do Carnaval em Belo Horizonte está inserido em um processo amplo de mudanças culturais e comportamentais da capital que precisam ser bem compreendidas para se traçar políticas públicas para o atendimento às necessidades da festa. $O$ Relatório do Carnaval no ano de 2015, elaborado pela Belotur, define que, para os órgãos públicos municipais, a evolução do Carnaval representa um desafio, tendo em vista a necessidade de se interpretar as mudanças sociais da festa e a adoção de políticas públicas de infraestrutura e logística urbana para abrigar o evento (BELOTUR, 2015).

Nesse cenário, mudanças foram identificadas no perfil da festa realizada na cidade, já a partir do ano de 2013. Por exemplo, houve crescimento do número de blocos de rua e a maior participação de foliões, em especial nas regiões Leste e Centro-Sul da capital mineira. A festa, naquele ano, reuniu um público de 500 mil pessoas e o valor investido pelo poder público municipal foi de $R \$$ 3,5 milhões (BELOTUR, 2013). 
Em 2014, o palco das atrações retornou ao seu local tradicional, a Avenida Afonso Pena, com o desfile dos blocos caricatos e das escolas de samba a partir de em um entendimento entre a Belotur e os carnavalescos da cidade. Naquele ano o Carnaval da cidade se consolidou como uma grande festa popular, com a participação de mais de um milhão de foliões, animados pela descontração dos blocos de rua. A festa também ganhou aporte financeiro da iniciativa privada (OLIVEIRA; WERNECK; FURBINO, 2014).

Em 2015, o Carnaval de Belo Horizonte entra na rota dos principais carnavais do Brasil, com um crescimento de 150\% do público em relação ao ano de 2013. Em 2015, cerca de 1,5 milhão de pessoas participaram da folia, configurando o Carnaval como o maior evento que a cidade já recebeu, superando em público a Copa do Mundo de 2014 (ANDRE, 2015). Para chegar a este patamar, o Carnaval passou por uma série de transformações nos três últimos anos, o que demandou intenso diálogo e planejamento por parte de seus agentes, sejam eles órgãos púbicos ou entidades privadas (BELOTUR, 2015).

O crescimento do evento na cidade está atrelado à organização dos blocos de rua. Nos últimos anos, o número de blocos se apresentando por várias regiões da cidade aumentou consideravelmente, o que levou o poder público municipal a efetuar atividades de articulação com os responsáveis pelos blocos. O objetivo era conscientizar os organizadores dos blocos a respeito da importância de se trabalhar em conjunto com a esfera pública para os preparativos das festividades (BELOTUR, 2015).

Mediante ao cenário apresentado, emerge o seguinte questionamento: "Como se estruturou a organização do Carnaval, enquanto festa popular, na cidade de Belo Horizonte?" Para responder ao questionamento, este trabalho objetiva analisar a organização Carnaval em Belo Horizonte entre os anos de 2013 e 2015. Ressalta-se que o período escolhido se justifica uma vez que, apesar de o movimento dos blocos de rua ter se iniciado em 2010, foi a partir de 2013 que o evento registrou importante aumento de público e demandou mais atenção do governo municipal e da iniciativa privada. Ainda, identifica-se que há poucos estudos publicados sobre a temática. Em uma busca pelos artigos a respeito da temática com a palavra "Carnaval", publicados nos últimos 10 anos nas bases de 
dados da Associação Nacional de Pós Graduação e Pesquisa em Administração (ANPAD), foram encontradas 11 publicações. Na base de dados da Scientific Periodicals Eletronic Library (SPELL), considerando-se os mesmos critérios, foram encontrados 16 artigos. Contudo, nenhum desses estudos apresentava a abordagem proposta neste artigo, que tratou especificamente do Carnaval da cidade de Belo Horizonte, terceira maior região metropolitana do país.

Nesse sentido, a pesquisa aqui proposta justifica-se por permitir ampliar os estudos até então realizados sobre o tema. Destaca-se, ainda, que os achados podem oferecer subsídios para o desenvolvimento de políticas públicas que visem ao aumento da atratividade e da competitividade turística de uma das três maiores cidades do país.

\section{BELO HORIZONTE: O CARNAVAL RENASCIDO PELAS MÃOS DA SOCIEDADE}

Os primeiros festejos carnavalescos em Belo Horizonte datam de 1897, antes mesmo de a capital ser inaugurada. Desde então esses foram envoltos por fantasias, confetes e sucessivas mudanças no endereço da folia (WERNECK, 2014). Segundo Pereira Filho (2006), a partir da inauguração da cidade, os clubes sociais surgem em várias partes da urbe, dinamizando a vida sociocultural da recente Belo Horizonte. Esses tinham como preocupação principal a viabilização de um Carnaval majestoso e requintado, sendo os carnavais de rua os grandes destaques dessas associações, pois os locais públicos tornavam-se uma espécie de palco festivo onde esses grupos manifestavam suas visões de mundo.

Em 1899 o Clube Diabos da Luneta promoveu importante desfile, com a participação de 22 carros alegóricos enfeitados que percorriam as ruas da cidade recém-criada. Nessa época, a Avenida Afonso Pena, no centro da cidade, transformava-se no palco dos desfiles de Carnaval. Segundo Teixeira (2005), nascia na capital mineira o tempo do elegante Corso e das Batalhas de Confetes, muito elogiado pela imprensa local e apreciado pela população da cidade.

O Corso Carnavalesco, ainda segundo Teixeira (2005), compreendia desfiles, inicialmente realizados em carroças ornamentadas com flores, que levavam 
bandas de música e foliões. Com a chegada dos automóveis, o desfile começou a contar também com carros automotivos enfeitados que traziam famílias fantasiadas. A festa, além de promover a participação popular, servia como forma de posicionamento social, pois, durante o cortejo, refletia-se a posição socioeconômica dos participantes, demonstrada pelo luxo dos ornamentos.

Em 1910, o Carnaval da capital foi animado pelo desfile de carros alegóricos. Existia uma diversidade nos carros, passando dos luxuosos aos modestos e até mesmo os improvisados, que eram adornados às pressas para sair às ruas e curtir a folia. Na década de 1920 consolida-se a guerra de serpentinas nos corsos, a guerra de confete nas calçadas e a de lança-perfume nos salões dos bailes e clubes das matinês da cidade. O Carnaval de Belo Horizonte, nessa época, era visto como elegante e criativo, apresentando participação de grande parte da população, principalmente nos bailes de clubes fechados que foram sendo cada vez mais procurados (TEIXEIRA, 2005).

Na década de 1930, tem-se registro da primeira escola de samba a desfilar em Belo Horizonte - a Pedreira Unida, formada por moradores da Pedreira Prado Lopes. O primeiro desfile das escolas de samba e blocos caricatos foi realizado na Avenida Afonso Pena, local usado até 1990, quando a Prefeitura passou a promover somente bailes populares de Carnaval (CARNAVAL DE BELO HORIZONTE, 2015).

Na década de 1940, os desfiles de fantasias nos bailes infantis e juvenis nos clubes da cidade, como o Automóvel Clube e o Clube Belo Horizonte, configuram-se como os mais importantes do evento. Portanto, considerandose o glamour e o status dos desfiles nos importantes clubes da cidade e, tendo em vista que os desfiles nos carros fechados, tradicionais no corso na Avenida Afonso Pena escondiam as fantasias, o povo passa a se organizar em grupos de ruas, como os blocos dos bairros (TEIXEIRA, 2005).

No final da década de 1940, tem-se o surgimento dos blocos caricatos e logo depois das escolas de samba. São criados os Blocos Caricatos pelos operários da cidade que pintavam os rostos e desfilavam batendo latas e tambores em cima das carroças (CARNAVAL DE BELO HORIZONTE, 2015). 
As batalhas de confete faziam mais sucesso a cada ano e, para participar, os foliões dos blocos dos bairros desciam para o centro da cidade, na maioria das vezes vestidos de mulher, o que inspirou, na década de 1970, a criação do mais tradicional bloco da cidade - a Banda Mole (TEIXEIRA, 2005). Além da criação da Banda Mole, entre as décadas de 1940 e 1980 não houve grandes acontecimentos que mudassem a caracterização do Carnaval na cidade e apenas na década de 1980 foi oficializado o Carnaval de Belo Horizonte por meio do Decreto Municipal n. 3.676/1980.

Ressalta-se que, desde sua criação, os desfiles do Carnaval da cidade eram realizados na Avenida Afonso Pena, o que perdurou por cinco décadas, sendo que na década de 1990 os desfiles do Carnaval passaram a ser realizados na Avenida do Contorno, na Via 240, no bairro Novo Aarão Reis e na Avenida dos Andradas (CARNAVAL DE BELO HORIZONTE, 2015).

Segundo Werneck (2014), com o fim dos desfiles na Avenida Afonso Pena, o Carnaval de Belo Horizonte deixou de promover o interesse da população, o que fez com que as administrações regionais da cidade promovessem bailes populares, especialmente voltados para o público infantil e terceira idade.

Apenas 20 anos mais tarde, em dezembro de 2013, por meio de uma parceria estruturada entre a Belotur, a Prefeitura de Belo Horizonte, as escolas de samba e os blocos de rua, os desfiles carnavalescos da cidade retornaram à Avenida Afonso Pena (WERNECK, 2014).

$\mathrm{Na}$ atualidade, jovens engajados têm se esforçado para mostrar que ocupar ruas e praças da cidade é prazeroso, saudável e, acima de tudo, direito de todos. Eles são, em sua maioria, músicos por formação e têm engajado parte importante de outros jovens em ensaios e desfiles dos blocos de rua (MUZZI, 2015). Nesse contexto, o ressurgimento do Carnaval em Belo Horizonte se deu de maneira espontânea (ASSIS, 2013), pelas mãos de amigos que se juntaram para [re]criar os blocos e fazer renascer o Carnaval. 


\section{A APROPRIAÇÃO DAS FESTAS POPULARES PELO TURISMO}

Segundo Amaral (1998), na área de ciências sociais existe uma escassez de reflexões teóricas sobre festas, estando elas inseridas em estudos e teorias voltados para a religião. A autora ainda salienta que o conjunto de estudos sobre festas está agrupado em subcapítulos, parágrafos e temas afins, dispersos não só em obras antropológicas, mas também filosóficas, sociologias, históricas, literárias, etc.

Toda festa, mesmo quando puramente laica em suas origens, tem certas características de cerimônia religiosa, pois em todos os casos ela tem por efeito aproximar os indivíduos, colocar em movimento as massas e suscitar assim um estado de efervescência, às vezes, mesmo de delírio que não é desprovido de parentesco com o estado religioso (AMARAL, 1998). Segundo a autora, as festas se revelam como um momento onde se obtêm a descontração, o desregramento, a revitalização histórica da identidade local. Sendo, por meio da festa, possível renovar as relações pessoais, os laços com o outro e entrar em contato com ideias e modos diferentes, estabelecendo novas possibilidades.

De forma diferenciada, o evento compreende todo fato ou acontecimento, espontâneo ou organizado, que ocorre na sociedade e, do ponto de vista do profissional, pressupõe planejamento e organização. Nesse aspecto o evento, quando nas mãos de um organizador profissional, passa a ser uma empresa dentro da empresa, com vida própria, que demanda planejamento, organização, execução e coordenação das atividades (CANTON, 1997).

Segundo dados do Ministério do Turismo (2010), os deslocamentos realizados com finalidades comerciais, e para a participação em eventos, ocorrem desde as antigas civilizações. No entanto, com a Revolução Industrial e com o desenvolvimento dos meios de comunicação e transporte, as viagens tomaram impulso no mundo, sendo incentivadas as viagens em prol de eventos com finalidades e interesses diversos (BRASIL, 2010). 
Cavenaghi et al. (2012) salientam que, com a influência do turismo, muitas festas e eventos no Brasil cresceram e ganharam visibilidade, pois o segmento permite que as populações locais saiam do papel passivo e de espectadoras e assumam um papel mais participativo, realçando os laços sociais. Nesse contexto, a inserção social acontece, pois as festas integram elementos constituidores das memórias individual e coletiva dos grupos sociais, reforçando a manifestação da identidade do lugar.

Em consonância a essas colocações, Melo (2001) salienta que as festas e os eventos tornam-se fenômenos de natureza socioculturais, uma vez que abrangerem distintas camadas sociais, significando uma trégua no cotidiano rotineiro e na atividade produtiva.

Sob essa perspectiva, os eventos constituem um universo à parte do cotidiano, que apresenta suas regras próprias, suspendendo a realidade costumeira do indivíduo. Melo (2001) destaca que as festas devem ser caracterizadas, especialmente, como um processo comunicacional, tendo em vista a relação delas com a mídia e seus conteúdos. Segundo o autor, a mídia dá uma "atenção especial" às festas populares tradicionais, o que acarreta um maior apelo turístico. Consequentemente, as comunidades buscam a mídia para a divulgação de suas atividades no mundo exterior, na expectativa de formar uma rede de relações sociais e ampliar os seus públicos.

Notavelmente o período de Pós-modernidade identifica-se um processo de mercantilização nos processos sociais. Cavenaghi et al. (2012) ressaltam que nesse contexto o turismo deixou de ser um privilégio da elite e passou a integrar o conjunto da população. Com este fenômeno, o número de turistas que passou a invadir as manifestações populares estabeleceu uma relação conflituosa com os moradores, por compartilhar recursos, mesmo que em um período curto, antes destinados a um grupo pequeno de indivíduos.

Para Amaral (1998), muitas festas populares brasileiras vêm se tornando atraentes no ponto de vista turístico, propiciando um mercado cada vez mais forte de empregos, produtos e serviços. O segmento turístico tem contribuído para a manutenção de expressões culturais, permitindo a permanência das festas, possibilitando às populações uma atuação mais participativa, reforçando e mantendo os laços 
sociais. Nesse sentido, eventos são grandes impulsionadores econômicos, dada sua capacidade de atingirem efeitos multiplicadores (GETZ, 1989, p. 125).

Trigueiro (2005) ressalta que, para atender ao mercado globalizado, de produção e consumo de bens materiais e imateriais, as manifestações culturais transformam-se em acontecimentos midiáticos, envolvendo redes de televisão, o interesse de grandes marcas de bebidas, de políticos, do turismo e até dos pequenos comerciantes temporários, que aproveitam as espetacularizações das festas para obter alguma renda.

\section{MARKETING TURÍSTICO E DE DESTINOS}

Todo destino turístico, como qualquer negócio, está imerso em um ambiente. Esse ambiente, que também pode ser conceituado como de ambiente de marketing, é o conjunto de atores e forças que afetam a capacidade da administração de desenvolver e manter relacionamentos bem-sucedidos com seus clientes (MTUR, 2015).

Portanto, para promover e incentivar a comercialização do turismo, as estratégias e as ações propostas pelos gestores do marketing devem ser capazes de intervir, de forma sustentável e equilibrada, no tecido urbano e no conjunto patrimonial. Além disto, o Marketing Turístico deve priorizar a população residente, possibilitando a sua inclusão no processo de planejamento, gestão e participação nos resultados (BESSA; TEIXEIRA, 2005).

Entretanto, nesse processo, para ser um território bom para moradores, investidores e visitantes, este espaço, ou lócus, precisa estar dotado de infraestrutura e de condições para atrair novos investimentos, propiciando o seu desenvolvimento urbano. Em face da crescente concorrência do turismo, as cidades precisam estar atentas para manter e ampliar seus investimentos. Atualmente, uma tendência importante é o desenvolvimento da herança cultural, da preservação da herança histórica dos lugares, das suas construções, povo, costumes e de tudo aquilo que garanta suas tradições (KOTLER et al., 2006).

A atração dos novos investimentos está atrelada a um conjunto de fatores que se compõe como diferenciais aos olhos do empresário que pretende se 
estabelecer em um novo destino. Elementos que reforçam a competitividade do lugar, como a infraestrutura física e comunicacional, a estabilidade política e social, qualidade de vida, são fatores determinantes. Com efeito, ganham importância nesse processo de venda da cidade o uso de técnicas publicitárias eficazes e a construção criativa de imagens (SANCHEZ, 1999).

No âmbito do marketing voltado para as estratégias no setor público, Xavier (2013) destaca que nas três últimas décadas houve maior valorização das pesquisas na área da Administração Pública, tendo em vista a ampliação do poder do Estado e sua responsabilidade social. Uma nova vertente de Administração, a vertente social, que sugere maior envolvimento da população na definição da agenda política, tem proporcionado maior controle social sobre as ações estatais e também a legitimação da sociedade como participante do processo de implementação de políticas públicas. Esse ambiente fez com que os estados passassem a se espelhar nas organizações administrativas do setor privado, voltando, assim, o interesse para as estratégias de marketing e, mais especificamente, de markebting de serviços.

O Estado possui, atualmente, a preocupação de transformar a prestação do serviço público em um produto que tenha presente em si o fator de qualidade, que proporcione satisfação, podendo gerar, por sua vez, uma imagem positiva do setor público (AQUINO, 2010). De forma paralela, toda sociedade precisa de um setor público que possa definir seus princípios operacionais. Portanto, o marketing torna-se uma importante ferramenta de planejamento para as empresas e órgãos públicos que queiram atender às necessidades e às demandas do cidadão (KOTLER; LEE, 2008), o que torna importante discutir a comunicação nas festas e nos eventos.

\section{COMUNICAÇÃO NAS FESTAS E NOS EVENTOS}

O Carnaval é uma das maiores festas populares do mundo. As festas populares ocupam lugar especial dentro das práticas nacionais de cultura, incorporando significados de acordo com suas especificidades regionais, e constituem-se em uma das linguagens favoritas do povo brasileiro, identificadas desde o Período Colonial pelos modos de relacionamento e comportamento (TEIXEIRA, 2005). 
Durante séculos, principalmente a partir do século XVII, o chamado jogo do entrudo seria a forma mais difundida de se brincar o Carnaval em terras brasileiras. Segundo Ferreira (2004), em qualquer uma das principais cidades, como São Paulo, Rio de Janeiro, Porto Alegre ou Florianópolis, o costume de se jogar água, pós, cinzas, águas de perfume, ou mesmo líquidos sujos sobre quem passasse por perto havia se tornado hábito na sociedade brasileira durante os dias dedicados às brincadeiras do Carnaval.

Trigueiro (2005) ressalta que, no início dos anos de 1970, com o crescimento da indústria cultural impulsionada pelos meios de comunicação de massa, principalmente da televisão, a espetacularização das culturas populares ou produtos culturais folkmidiáticos se intensifica e ganha visibilidade no Brasil. Para o autor, a folkcomunicação é a incorporação das manifestações culturais populares pela mídia e, em movimento inverso, como os protagonistas das culturas populares se apropriam das novas tecnologias para reinventarem os seus produtos culturais.

Nesse sentido, identifica-se a existência de duas festas, uma dentro da outra, ou seja, a festa central institucionalizada, de interesse econômico dos megagrupos empresariais, políticos e até religiosos, e a outra periférica, que continua sendo organizada por meio da mobilização da comunidade, pelas fortes redes sociais de comunicação, com a finalidade alegórica de rompimento com o cotidiano e com o mundo normativo estabelecido (TRIGUEIRO, 2005).

Para o autor, as festas populares já não pertencem mais apenas aos seus protagonistas, passando a ser de interesse dos grupos midiáticos, dos empresários do turismo, do entretenimento e das empresas de bebidas, comidas e outros produtos de consumo. Em termos agregados, nota-se uma mediação midiática fortemente influenciada pela televisão, que se apropria das manifestações das culturas populares para os seus mais diversos interesses.

Nesse sentido os processos comunicacionais representam um elemento mediador na determinação de fluxos turísticos, sendo, portanto, um dos principais meios de veiculação de imagens e de informação sobre destinos (ZUCCO; REIS, 2010). 


\section{COMUNICAÇÃO COMO ESTRATÉGIA DE VISIBILIDADE PARA}

CIDADES E DESTINOS

Ao longo dos anos, o turismo tem ganhado proporções em todo mundo e, consequentemente, passou a receber atenção especial dos governos de países, estados e cidades que possuem representativo fluxo de visitantes ou que apresentam potencial para a prática da atividade turística. O desenvolvimento do turismo acarreta aumento da competitividade, o que leva à disputa entre destinos por mercados consumidores. Nesse ambiente, a imagem dos destinos é essencial (FIGUEIREDO; MAYER, 2010).

Nesse aspecto, os gestores das políticas urbanas utilizam vários aparatos de comunicação, por meio de estratégias atrativas de divulgação, capazes de transmitir os benefícios do produto oferecido, que, nesse caso, é a cidade, ou o destino turístico. Nesse contexto, o discurso de comunicação está voltado para o envolvimento do cidadão nos projetos de renovação da cidade. Portanto, as ações de comunicação precisam proporcionar à maioria da população um sentimento de orgulho e de pertencimento à cidade, o que gera mais do que uma participação ativa, como também uma participação contemplativa da nova cidade (SANCHÉS, 1999, p. 127).

Elementos que reforçam a competitividade do lugar, como a infraestrutura física e comunicacional, a estabilidade política e social, a qualidade de vida, são fatores determinantes para manter os destinos turísticos competitivos. Com efeito, ganham importância nesse processo de venda da cidade o uso de técnicas publicitárias eficazes e a construção criativa de imagens (SANCHEZ, 1999).

Corroborando esse posicionamento, Minciotti e Silva (2010) pontuam que todas as regiões e cidades precisam oferecer produtos e serviços sociais de forma eficiente e acessível para suas comunidades como vantagens diferenciadoras. De acordo com os autores, o marketing aplicado ao setor público não pode referir-se apenas à promoção e à comunicação do país, estado, regiões ou cidades. É neste ambiente que surge uma abordagem de marketing um pouco diferente das abordagens tradicionais: o Marketing de Localidades, que objetiva 
aproximar e estreitar o relacionamento entre o governante, a comunidade e os seus atores locais, com o intuito de promover trocas, cujo território - ou localidade - é o objeto principal. Portanto, o desafio do Marketing de Localidades é "fortalecer a capacidade das comunidades e das regiões de se adaptarem ao mercado mutante, aproveitar oportunidades e manter sua vitalidade" (MINCIOTTI; SILVA, 2010, p. 331).

Nesse contexto, Kotler et al. (2006) apresentam o 'Marketing Estratégico de um Local', cujo foco está na reconstrução e no incremento de cidades, regiões, estados e países. Sob essa ótica a comunidade deve ser trabalhada para que ela satisfaça as necessidades dos seus cidadãos. O Marketing Local é bem-sucedido quando os contribuintes, tais como os cidadãos, os trabalhadores e as empresas, obtêm satisfação da comunidade e, ainda, quando os seus visitantes e investidores têm suas expectativas atendidas ou superadas (KOTLER et al., 2006).

Sob esse prisma, o lugar é o produto, e os fatores de marketing são as estratégias utilizadas para atrair os públicos-alvo (MINCIOTTI; SILVA, 2010). Essas estratégias, segundo os autores, mostram a competência de uma localidade vender a imagem da sua população pelas mais diferentes formas, como a hospitalidade ou os seus talentos locais.

Nesse sentido, reportam-se as colocações de Sanchez (1999), segundo o qual na ótica das políticas de promoção e divulgação das cidades e de criação e ampliação de imagem, as políticas de comunicação são consideradas um importante instrumento de planejamento, resultante do redesenho de estratégias urbanas, o que pode acorrer com o planejamento do Carnaval em suas diversas dimensões.

METODOLOGIA

A presente pesquisa foi construída à luz de uma abordagem qualitativa e, quanto aos fins, se caracteriza como um estudo descritivo. Esse tipo de estudo, segundo Vergara (2009, p. 42), "expõe características de determinada população ou de determinado fenômeno". Nesse estudo, mais especificamente, o fenômeno de estudo consiste no Carnaval de Belo Horizonte.

O lócus escolhido para a pesquisa foi a cidade de Belo Horizonte, onde foi realizada uma pesquisa documental, com base em um levantamento nos 
arquivos Belotur, onde foram encontrados documentos, portarias e relatórios do Carnaval na cidade.

Como delimitação das fontes pesquisadas, optou-se pelas publicações veiculadas nos jornais Estado de Minas, Hoje em Dia e O Tempo, que são os principais periódicos impressos da cidade, além dos relatórios institucionais da Belotur, todos circunscritos aos balanços do evento carnavalesco dos anos de 2013 a 2015. Foram localizadas 22 reportagens veiculadas nas mídias selecionadas, sendo: 14 no Jornal Estado de Minas; quatro no Jornal O Tempo; quatro no Jornal Hoje em Dia. Dos relatórios da Belotur, foram analisados os Relatórios de Atividades de 2013, 2014 e 2015.

Durante a realização da pesquisa foram selecionadas reportagens jornalísticas cujo conteúdo tratava, principalmente, dos resultados do Carnaval nos anos de análise. Buscou-se selecionar notícias que falavam sobre o público da festa, a programação do evento, o desfile das escolas de samba, os blocos de ruas e os blocos caricatos, além da infraestrutura disponibilizada pelo poder público municipal.

Após a coleta dos dados, os mesmos foram organizados e analisados tendo por base os preceitos da análise documental. Segundo Helder (2006, p.1), "a técnica documental vale-se de documentos originais, que ainda não receberam tratamento analítico por nenhum autor. [...] é uma das técnicas decisivas para a pesquisa em ciências sociais e humanas". Nesse sentido, tal técnica foi escolhida para a análise de dados, uma vez que ela, segundo Cellard (2008), possibilita que o processo de evolução de indivíduos, conceitos, grupos, comportamentos, práticas, mentalidade, dentre outros, seja observado, analisado e compreendido.

RESULTADOS DA PESQUISA

\section{O CARNAVAL DE BH EM 2013}

Mesmo com todo o movimento dejovens se organizando e saindo fantasiados pela cidade durante o Carnaval de 2010, foi em 2013 que Belo Horizonte experimentou uma grande concentração de pessoas pelas ruas e registrou um 
público de 500 mil foliões. Segundo dados da Belotur (2013), para o Carnaval de 2013 estavam cadastrados 42 blocos de rua, entretanto 72 desfilaram, fato que causou surpresas tanto para o poder público quanto para os organizadores dos blocos. No Bairro Santa Tereza, por exemplo, na Região Leste de Belo Horizonte, um dos locais de maior aglomeração de foliões e para onde estavam previstos oito blocos, foram destinados 19. Naquele ano, o máximo esperado de público para um bloco era de 1,5 mil pessoas, mas em alguns casos, como no bloco "Baianas Ozadas", este número chegou a 12 mil (OLIVEIRA; KREFER, 2013).

Nesse período o Carnaval belohorizontino encontrava-se em meio a um acentuado processo expansionista, fato que abriu precedentes para que o evento na cidade ganhasse notoriedade frente aos órgãos públicos, à iniciativa privada e à própria comunidade.

Apesardesse processo, alguns pontos decriticidade puderamseridentificados. Dentre tais destacam-se alguns transtornos gerados pela folia aos moradores do Bairro Santa Tereza, como excesso de barulho, sujeira, ocupação desordenada das ruas do bairro e falta de banheiros químicos, como intitula manchete do Jornal Estado de Minas "Lições de um carnaval renascido - Multidão nas ruas mostram que é preciso mais estrutura para a folia".

O desfile das escolas de samba e dos blocos caricatos foi realizado dentro do Espaço da Estação do Samba na Avenida dos Andradas. Participaram naquele ano nove blocos caricatos e seis escolas de samba (BELOTUR, 2013). A Estação do Samba, montada pelo terceiro ano consecutivo, foi realizada na Praça da Estação, com shows de bandas de samba e ritmos do Carnaval (BELOTUR, 2013). Ao poder público municipal coube cuidar da organização, apoio logístico e fornecimento de equipamentos e serviços para o evento. Em 2013 a Prefeitura Municipal de Belo Horizonte aplicou R\$ 3,5 milhões em ações de estruturação e produção do Carnaval na capital mineira.

Após a realização do Carnaval, uma série de problemas, principalmente relacionados à infraestrutura, foi evidenciada. O Jornal O Tempo traz notícia sugerindo uma reavaliação da festa. "Lixo amontoado, urina nas ruas, bancos quebrados e até uma estátua depredada. Esse foi o cenário de Belo Horizonte após o desfile de 72 blocos por 20 bairros da capital". O periódico afirma que, 
mesmo com as instalações de banheiros químicos, ainda houve reclamações da festa pelos moradores e foliões.

Como resposta aos problemas apresentados em 2013, o representante da Belotur salientou que o fenômeno pede mais planejamento para o próximo ano (OLIVEIRA; KREFER, 2013, p.17). Portanto, para evitar os mesmos transtornos ocorridos em 2013, na semana seguinte ao evento, os órgãos inseridos na organização da festa, representantes dos blocos de rua, polícias Civil e Militar, reuniram-se para programar a festa de 2014 (OLIVEIRA; KREFER, 2013).

O balanço da festa, segundo o Jornal Estado de Minas, aponta o que deu certo: animação, convivência pacífica e grande diversidade de blocos. O "que deu errado", de acordo com o veículo, foram o número insuficiente de banheiros químicos, a falta de lixeira e o plano de trânsito que não atendeu à demanda (OLIVEIRA; KREFER, 2013, p.17). Tais acontecimentos refletiram a falta de estrutura e planejamento da cidade para realização de eventos de grande porte. Contudo, deu indícios do que precisava ser melhorado para os anos seguintes.

\section{O CARNAVAL DE BH EM 2014}

Devido ao relativo "sucesso" do Carnaval de 2013, no do ano de 2014 o evento já apresentava, em seu primeiro dia, um considerável aumento de público. Para atender à população que passou a ocupar as ruas da cidade, o Carnaval de Belo Horizonte, em 2014, ganhou um novo formato.

Uma das principais mudanças em relação ao ano anterior foi a transferência dos desfiles das agremiações para a Avenida Afonso Pena, no centro da capital mineira. Tal transposição se deu em função de uma reivindicação dos organizadores dos blocos caricatos e das escolas de samba. Segundo a Belotur (2014), nove blocos caricatos e seis escolas de samba apresentaram-se, durante dois dias, com estrutura de cercamento, barracas de alimentação, sanitários, arquibancadas e iluminação.

Foi também em 2014 que o Carnaval da cidade se consolidou como uma grande festa popular. Como reflexo do Carnaval de 2013, identificou-se que o folião se sentia mais seguro para participar do evento. Tal fato pode ser 
evidenciado pelo público que se reuniu (mais de um milhão de pessoas - o dobro do ano anterior) - para acompanhar os desfiles dos blocos e das escolas de samba (OLIVEIRA; WERNECK; FURBINO, 2014).

Neste ano o evento recebeu um investimento de $\mathrm{R} \$ 5,5$ milhões, $43 \%$ a mais que o valor investido em 2013. E, pela primeira vez na história, o Carnaval da cidade passou a contar, oficialmente, com patrocínio da iniciativa privada, por meio de uma cervejaria.

Neste contexto, "o Carnaval transformou-se na maior festa da cidade" (BELOTUR, 2014, p. 18), extrapolando as fronteiras até então definidas para o evento. De acordo com Relatório de Atividades da Belotur (2014), a Estação do Samba - palco com programação de shows e bandas carnavalescas - que nos dois anos anteriores era montada na Praça da Estação, passa a ocupar todas as regiões da cidade. Foram construídos 14 palcos da Estação do Samba, instalados nos principais pontos de aglomerações de pessoas na região central e nas nove Regionais Administrativas ${ }^{1}$ da cidade. Estes palcos abrigaram 91 shows e atividades carnavalescas.

Nesse sentido nota-se que o Carnaval de Belo Horizonte passa a ser pensado de maneira estratégica, tanto pelo poder público quanto pelos organizadores de blocos. Identificam-se características do marketing de localidade dado que, de acordo com Minciotti e Silva (2010), o lugar é o produto, e as ações de marketing são as estratégias utilizadas para estreitar o relacionamento entre o governante, a comunidade e os seus atores locais, com o intuito de interagir e promover trocas.

Os desfiles dos blocos de rua, fenômeno espontâneo e que em 2014 demandaria maior atenção do poder público, tendo em vista os problemas ocorridos em 2013, foi um dos principais pontos do planejamento da festa. Com objetivo de organizar e ter uma visão geral das apresentações dos blocos, a Belotur abriu credenciamento pelo site institucional do Carnaval, o que permitiu o mapeamento da ocupação do espaço público e orientou as definições sobre

1 As Regiões Administrativas de Belo Horizonte são subdivisões gerenciais do Município, sendo elas: Barreiro, Centro-Sul, Leste, Nordeste, Noroeste, Norte, Oeste, Pampulha e Venda Nova. Essa divisão atende à necessidade por descentralização e coordenação de programas e atividades adequados às particularidades de cada região da cidade. 
infraestrutura, limpeza urbana, segurança e trânsito. Em 2014, 168 blocos de rua se cadastraram para desfilar nas ruas da cidade, 96 a mais que no ano anterior. Entretanto, o poder público municipal estima que mais de 200 blocos se apresentaram (BELOTUR, 2014).

Um dos pontos importantes a se ressaltar é a criação da Comissão Especial do Carnaval, que visava integrar os órgãos e as ações da Prefeitura Municipal na organização e no planejamento do Carnaval de BH 2014. O objetivo principal dessa comissão era sanar os problemas ocasionados em 2013 com a falta de banheiros químicos, o número de equipamentos instalados passou para 4,5 mil diárias.

Destaca-se ainda que o ano de 2014, apesar de algumas falhas de planejamento, representou um grande avanço no planejamento do evento (ROCHA, 2014).

No bairro Santa Tereza, que em 2013 foi o epicentro dos problemas do evento, recebeu atenção especial dos moradores, organizadores dos blocos de rua e do poder público municipal. Foram feitas, em conjunto com a comunidade, ações de comunicação, segurança e infraestrutura voltadas para o bairro. Ayer (2014) salienta que, no ano de 2014, a prefeitura da cidade adotou algumas medidas, dentre as quais se destaca que a festa só poderia ser realizada no período diurno e o fechamento das ruas de maior movimento no bairro. Outra medida a ser sublinhada foi o reforço no policiamento em toda a programação oficial carnavalesca prevista para o bairro (BELOTUR, 2014).

Nesse contexto, nota-se que as ações de comunicação estão inseridas nas estratégias de organização e planejamento do evento, buscando atender às demandas do cidadão e dos demais públicos da festa, o que corrobora as colocações de Sanchés (1999), que afirma que estas ações devem ser estruturadas no sentido de engajar a população em prol do sucesso do evento.

\section{O CARNAVAL DE BH EM 2015}

Como resultado de um processo ascendente, em 2015 o carnaval de Belo Horizonte insere-se no roteiro dos grandes carnavais das capitais brasileiras, 
tornando-se o maior evento de toda a história da capital, se considerado o número de participantes $-1,5$ milhão de pessoas esteve presentes nas atividades programadas para o evento (BELOTUR, 2015).

A festa ganhou novo slogan "Carnaval de BH - A Casa é Sua e a Festa Também", a frase trata-se de "um convite ao diálogo com os moradores da cidade, que fazem a festa ganhar maior proporção e se tornar mais democrática e popular, e os turistas que vem para a cidade em busca de entretenimento e da hospitalidade mineira" (BELOTUR, 2015, p. 3). Nesse sentido, em consonância com as colocações de Sanchés (1999), identifica-se uma tentativa das ações de comunicação em criar uma familiarização das pessoas com o ambiente e o evento, tentando resgatar no folião características peculiares de Minas.

Para a realização das ações vinculadas ao Carnaval da cidade em 2015, o poder público municipal investiu $\mathrm{R} \$ 5,45$ milhões, entre recursos próprios e de patrocinadores. Pela segunda vez, uma cervejaria foi a patrocinadora oficial da folia, que contou ainda com o patrocínio de uma empresa de telefonia, de uma entidade do comércio e de um site de entretenimento (BELOTUR, 2015).

Para as festividades da Estação do Samba, foram distribuídos 14 palcos pela cidade. Foram 92 apresentações artísticas e 18 Dj's no palco da Savassi. O tradicional desfile dos blocos caricatos e das Escolas de Samba foi, novamente, realizado na Avenida Afonso Pena, e atraiu um público de 50 mil pessoas (BELOTUR, 2015). Foram cadastrados 177 blocos de rua, mas o poder público contabilizou que 200 se apresentaram pela cidade (PELEGRINI, 2015).

Em 2015, os blocos de rua de Belo Horizonte cresceram, se organizaram e fizeram do carnaval da capital mineira um evento de grande porte (HOJE EM DIA, 2015). "O diferencial dos blocos de rua é propiciar um movimento espontâneo, familiar/tribal, mais seguro, alegre e cidadão, com melhor custo/ benefício para todos os participantes" (BELOTUR, 2015, p. 2).

Alguns blocos arrastaram verdadeiras multidões de pessoas pelas ruas da cidade, durante o período momesco². Braga (2015) destaca que no sábado de carnaval o bloco "Então brilha" concentrou 20 mil pessoas. No domingo, o "Alcova Libertina" levou mais de 30 mil foliões as ruas. O destaque em 2015 ficou

2 Período relativo aos três dias de carnaval.

Revista Turismo - Visão e Ação - EletrônicA, Vol. 18 - N. 2 - MAi. - AGo. 2016 
para o bloco "Baianas Ozadas", que fez história no carnaval de Belo Horizonte ao reunir, na segunda-feira da folia, mais de 100 mil pessoas entre a concentração da Praça da Liberdade e a dispersão na Praça da Estação (BRAGA, 2015).

O carnaval 2015 adquiriu mais um atrativo ao criar pacotes turísticos para as pessoas que pretendiam visitar a capital durante a folia (OLIVEIRA, 2015). Com blocos de rua animando toda a cidade, indo dos maiores que arrastaram multidões àqueles menores com algumas centenas de pessoas, a cidade agradou aos turistas por oferecer preços em conta, folia aberta ao público (sem necessidade de abadás), e hospitalidade (MARZANO; WERNECK; FONSECA, 2015).

A festa passou a ter repercussão nas atividades empresariais e econômicas da cidade, em especial nos prestadores de serviço, na hotelaria, na gastronomia, nas agências de viagem. Houve crescimento médio de $50 \%$ na procura de serviços turísticos para o período, e aumento de $20 \%$ na venda de serviços (passeios, traslados, etc.) no período do Carnaval (BELOTUR, 2015). Nesse contexto, assim como ressaltado por Cavenaghi et al. (2012), o Carnaval em Belo Horizonte se diferenciou dos de outras capitais brasileiras por não ser visto apenas como um privilégio das elites, dado que os visitantes puderam participar gratuitamente de qualquer manifestação realizada, ou seja, tratavase de uma festa verdadeiramente popular.

Em 2015 também foi anunciado o monitoramento, pela primeira vez, de toda a movimentação da cidade durante a festa. Uma notícia do Jornal Estado de Minas, um mês antes do carnaval, anunciava que cerca de mil câmeras seriam instaladas para segurança dos foliões. Tudo que ocorresse nas ruas contaria com o acompanhamento do Centro de Operações de Belo Horizonte (COP-BH) em articulação com os órgãos da Comissão Especial do Carnaval. O monitoramento permitiu um rápido reposicionamento de equipes e reorientações de ações preventivas e corretivas. Nenhuma ocorrência policial grave ocorreu durante a festa dentre as 55 registradas. Não houve danos ao patrimônio e para controle da festa foram destacados 4.070 policiais (BELOTUR, 2015).

O problema da sujeira nas ruas, antes visto somente como responsabilidade do poder público, em 2015 passa a ser compartilhado com o cidadão. "Belo Horizonte já tem carnaval. O que falta agora é educação por parte de muita gente. 
Tem sujeito à beça fazendo cantos e beiradas de privada - apesar dos banheiros químicos espalhados pelos quarteirões de algazarra" (COUTINHO, 2015, p.1).

Mesmo tendo aumentado em 125\% o número de banheiros químicos, passando de 4 mil para 9 mil instalações, ainda houve reclamações. Segundo representante do poder público municipal, a falta de banheiros tem a ver com a distribuição espacial das cabines, fato que deve ser corrigido no próximo ano (WERKEMA, 2015, p. 16).

Destaca-se ainda a tentativa de se discutir questões de responsabilidade social, como a realização de campanhas educativas sobre o consumo consciente de água (LIRA, 2015), descarte correto de lixo e utilização correta dos banheiros químicos instalados em todos os espaços com programação carnavalesca (BELOTUR, 2015).

Notavelmente a reafirmação do Carnaval de Belo Horizonte como um dos maiores do país se deu pelas mãos da sociedade, não que as ações do poder público devam ser desmerecidas, mas o evento na cidade pode ser visto como um processo de reconstrução social.

O Quadro 1 destaca os principais pontos do Carnaval de Belo Horizonte nas três edições analisadas, identificando os principais fatores críticos do evento e as respectivas ações implementadas.

Quadro 1 - Evolução do Carnaval de Belo Horizonte (2013 a 2015)

\begin{tabular}{|c|c|c|c|}
\hline AÇÃO & 2013 & 2014 & 2015 \\
\hline Público & 500 mil pessoas & 1 milhão de pessoas & 1,5 milhão de pessoas \\
\hline Investimento & $\begin{array}{c}\text { - } \mathrm{R} \$ 3,5 \text { milhões } \\
\text { - Recursos da Prefeitura } \\
\text { de Belo Horizonte }\end{array}$ & $\begin{array}{l}\text { - R\$ 5,5 milhões } \\
\text { - Recursos da } \\
\text { Prefeitura } \\
\text { - Patrocínio - } \\
\text { cervejaria }\end{array}$ & $\begin{array}{c}\text { - R\$ 5,45 milhões, } \\
\text { - Recursos da Prefeitura } \\
\text { - Patrocínios - cervejaria, } \\
\text { empresa de telefonia, } \\
\text { entidade do comércio e site de } \\
\text { entretenimento. }\end{array}$ \\
\hline $\begin{array}{l}\text { Bairro Santa } \\
\text { Tereza }\end{array}$ & $\begin{array}{l}\text { - Faltaram banheiros, } \\
\text { - Garrafas de vidro } \\
\text { - Problemas no trânsito, } \\
\text { - Sujeira } \\
\text { - Pouca fiscalização }\end{array}$ & $\begin{array}{c}\text { - Sensibilização } \\
\text { - Fechamento das } \\
\text { ruas } \\
\text { - Festa diurna } \\
\text { - Aumento de } \\
\text { banheiros } \\
\text { - Reforço policial }\end{array}$ & $\begin{array}{l}\text { - Fechamento das ruas } \\
\text { - Festa diurna } \\
\text { - Sem problemas graves }\end{array}$ \\
\hline $\begin{array}{c}\text { Desfile das } \\
\text { Escolas de Samba } \\
\text { e dos Blocos } \\
\text { Caricatos }\end{array}$ & $\begin{array}{l}\text { - Local - Estação do } \\
\text { Samba } \\
\text { - Público - oito mil } \\
\text { pessoas }\end{array}$ & $\begin{array}{l}\text { - Local - Avenida } \\
\text { Afonso Pena }\end{array}$ & $\begin{array}{l}\text { - Local - Avenida Afonso Pena } \\
\text { - Público - de } 50 \text { mil pessoas }\end{array}$ \\
\hline
\end{tabular}


DoI: 10.14210/rtva.v18n2.p251-279

\begin{tabular}{|c|c|c|c|}
\hline $\begin{array}{l}\text { Estação do } \\
\text { Samba }\end{array}$ & $\begin{array}{c}\text { - Local - Praça da } \\
\text { Estação } \\
\text { - Palcos - um } \\
\text { - Atrações - shows e } \\
\text { desfiles das escolas de } \\
\text { samba e blocos caricatos }\end{array}$ & $\begin{array}{c}\text { - Local - Todas as } \\
\text { regiões } \\
\text { - Palcos - } 14 \\
\text { - Atrações - } 91 \text { shows } \\
\text {. }\end{array}$ & $\begin{array}{c}\text { - Local - Todas as regiões } \\
\text { - Palcos - } 13 \\
\text { - Atrações - } 91 \text { shows } \\
\text { - Torre de Djs na Savassi }\end{array}$ \\
\hline $\begin{array}{l}\text { Desfile dos } \\
\text { Blocos de Rua }\end{array}$ & - Número oficial - 72 & $\begin{array}{l}\text { - Número oficial - } \\
168 \\
\text { - Estimativa - } \\
200 \text { blocos se } \\
\text { apresentaram. } \\
\text { - Cadastramento } \\
\text { através de site }\end{array}$ & $\begin{array}{l}\text { - Número oficial - } 177 \\
\text { - Estimativa - mais de } 200 \\
\text { blocos } \\
\text { - Cadastramento através de } \\
\text { site } \\
\text { Crescimento e organização } \\
\text { Mobilização de multidão }\end{array}$ \\
\hline $\begin{array}{l}\text { Banheiros } \\
\text { químicos }\end{array}$ & 650 instalações & 4,5 mil instalações & 9 mil instalações \\
\hline $\begin{array}{l}\text { Comissão Especial } \\
\text { do Carnaval }\end{array}$ & - Não havia & $\begin{array}{c}\text { - Criada através de } \\
\text { Portaria Conjunta } \\
\text { N001 }\end{array}$ & $\begin{array}{c}\text { - Participação do Centro de } \\
\text { Operações de Belo Horizonte } \\
\text { (COP) } \\
\text { - Monitoramento da cidade } \\
\text { - Ações preventivas e } \\
\text { corretivas. }\end{array}$ \\
\hline $\begin{array}{c}\text { Repercussão no } \\
\text { Turismo }\end{array}$ & Não havia & $\begin{array}{l}\text {-L Crescimento na } \\
\text { ocupação hoteleira } \\
\text { - Aumento no } \\
\text { movimento de bares } \\
\text { e restaurantes }\end{array}$ & $\begin{array}{l}\text { - Criação de pacotes turísticos } \\
\text { - Crescimento médio de } \\
50 \% \text { na procura de serviços } \\
\text { turísticos } \\
\text { - Aumento de } 20 \% \text { na venda } \\
\text { de serviços turístico. }\end{array}$ \\
\hline
\end{tabular}

Fonte: Desenvolvido pelos autores.

Salienta-se que o planejamento antecipado da festa é uma das necessidades apontadas pelos atores inseridos na organização do Carnaval da cidade. Alguns organizadores de blocos de rua sugerem uma legislação especial para o período. Caetano (2014) destaca que montar uma comissão permanente para o Carnaval, voltada para quem tem interesse no tema, é uma forma de dar transparência ao que está sendo planejado para a festa no ano seguinte. Corroborando essas colocações, o poder público municipal ressalta que "a dimensão das manifestações, em número e porte de participantes, exige permanente ampliação, antecipação, integração e aprofundamento do planejamento para 2016, com base em intenso diálogo e parcerias produtivas" (BELOTUR, 2015, p.3).

Nesse sentido, sublinha-se ainda a necessidade de normatização de alguns procedimentos por meio de legislação municipal ou regulamentação anual, como o conceito de eventos e blocos de rua, trio elétrico e bloco espontâneo, 
maiores informações sobre blocos de rua, conforme previsto no relatório do Carnaval 2015.

\section{CONSIDERAÇÕES FINAIS}

Este estudo teve como objetivo analisar as ações empreendidas no Carnaval de Belo Horizonte entre os anos de 2013 e 2015. Para alcance dos resultados, foram analisadas notícias jornalísticas nos Jornais O Tempo, Hoje em Dia e Estado de Minas, veiculadas durante o período da festa momesca nos anos em análise. Também foram analisados os relatórios de atividades da Belotur, empresa municipal de turismo que organiza a festa em Belo Horizonte.

Constatou-se que a presença popular na festa do carnaval na cidade de Belo Horizonte, nos três últimos anos, cresceu e despertou o interesse da iniciativa privada, passando a integrar a lista das principais festas populares do país. Com a oferta de pacotes turísticos e o aumento quantitativo de público, caracterizouse como um evento turístico, com repercussão nas atividades empresariais e econômicas da cidade, em especial nos prestadores de serviço, na hotelaria, na gastronomia, nas agências de viagem.

O envolvimento de vários agentes, como poder público municipal, patrocinadores, carnavalescos e organizadores de blocos de ruas, fez-se necessário para o fornecimento de infraestrutura urbana, logística e a diversa agenda de entretenimento do evento.

Os blocos de rua, que são o grande atrativo do carnaval da cidade, vêm crescendo em número e em adesão de foliões. Enquanto em 2013 o público do carnaval reuniu 500 mil pessoas, em 2015 o número triplicou, atingindo 1,5 milhão de pessoas reunidas em torno da programação carnavalesca da cidade. O bloco "Baianas Ozadas", por exemplo, atraiu 10 mil foliões em 2013 e em 2015 estima-se que 100 mil pessoas acompanharam o seu desfile.

O Bairro Santa Tereza, em Belo Horizonte, que foi o centro dos principais problemas causados pela festa em 2013, já em 2015 não registrou ocorrências graves. Acreditase que a estratégia de dimensionar a festa em diferentes pontos da cidade, tirando a concentração desse bairro boêmio, tenha contribuído com esses resultados. 
O desfile das escolas de samba e dos blocos caricatos voltou, em 2014, para o coração da cidade, na Avenida Afonso Pena - o cenário principal do carnaval no início da construção da capital, o que perdurou até a década de 1940.

Os investimentos gerais da festa cresceram. Enquanto em 2013 a programação da folia na cidade recebeu $R \$ 3,5$ milhões, em 2015 o investimento foi 56\% maior, chegando a $R \$ 4,25$, com recursos do poder público e, a partir de 2014, também da iniciativa privada.

Mesmo com o incremento do investimento em banheiros químicos e o aumento de instalação dos equipamentos, o número de cabines ainda é insuficiente, tendo em vista o aumento, ano a ano, do público participante do evento.

Evidenciou-se a necessidade do contínuo diálogo entre os agentes realizadores do evento, órgãos e entidades envolvidas com a organização da festa. A criação de uma legislação municipal que normatize o carnaval de Belo Horizonte é uma necessidade comum entre os atores inseridos no evento.

As limitações do estudo estão no fato de se analisar somente um período restrito do carnaval da cidade. O tema poderia ser objeto de análise para várias áreas da Administração, voltado para o marketing, gestão pública, além de outras áreas das ciências, como sociologia e comunicação.

\section{REFERÊNCIAS}

ANDRE, H. E BH Carnavalizou. Maior festa da cidade embalou foliões com maracatu, axé, funk e samba. Hoje em Dia, p. 12. 18 fev. 2015.

AMARAL, R. C. M. P. Festa à Brasileira: significados do festejar num país 'que não é sério'. São Paulo, Tese de doutoramento apresentada ao departamento de Filosofia, Letras e Ciências Sociais da USP, 1998.

AQUINO, J. M. C. Identificação e imagem do serviço público: um estudo com os usuários do Tribunal de Justiça do Estado de Minas Gerais. 2010. 101 f. Dissertação (Mestrado em Administração). Faculdade de Administração, Universidade Fundação Mineira de Educação e Cultura, Belo Horizonte. 2010.

ASSIS, S. Coorganizadora do Bloco Tico-Tico do Serra Copo. Entrevista para o Jornal 
Estado de Minas. 14 fev. 2013. p.17.

AYER, Flávia. Aposta alta na folia. Estado de Minas. Belo Horizonte. 14 fev. 2014. Caderno Gerais p. 19.

BESSA, A. S. M.; TEIXEIRA, L.A. A. Marketing turístico urbano e intervenção patrimonial em tempos de globalização. Revista Turismo - Visão e Ação, v. 7, n. 3, p. 539-1547, 2005.

BRAGA, C. Foi de arrepiar. Estado de Minas. Belo Horizonte, 17 fev. 2015. Caderno especial p. 2.

BRASIL. Ministério do Turismo - MTUR. Marketing de Destinos Turísticos. Brasília, publicado em 26 maio 2015. 72 p. Disponível em: < http://www.turismo.gov.br/sites/default/ turismo/o_ministerio/publicacoes/downloads_publicacoes/Marketing_Destinos_Turisticos. pdf>. Acesso em: 29 fev. 2016.

CAETANO, G. Fundador do Bloco Unidos do Samba Queixinho. Entrevista para o Jornal 0 Tempo, 19 fev. 2014. p.20.

CARNAVAL DE BELO HORIZONTE. Histórico. Disponível em:<http://www. carnavaldebelohorizonte.com.br/historia/>. Acesso em 27 Jun. 2015.

CELLARD, A. A análise documental. In: POUPART, J. et al. A pesquisa qualitativa: enfoques epistemológicos e metodológicos. Petrópolis, Vozes. 2008.

COUTINHO, J. F. Descompasso na avenida. Estado de Minas. Belo Horizonte, 15 fev. 2015. Caderno Especial, p. 1-5.

EMPRESA MUNICIPAL DE TURISMO - BELOTUR. Assessoria de Comunicação. Prefeitura de Belo Horizonte (Org.). Resumo da História do Carnaval em Belo Horizonte. 2011. Disponível em: <http://portalpbh.pbh.gov.br/pbh/ecp/comunidade.do?evento=portlet\&pIdPlc=ecpTaxonomia MenuPortal\&app=carnaval2011\&lang=pt_BR\&pg=8701\&tax=22371 >. Acesso em: 10 jul. 2014.

EMPRESA MUNICIPAL DE TURISMO - BELOTUR. Relatório de Atividades 2013. Belo Horizonte, 2013. 55 p.

EMPRESA MUNICIPAL DE TURISMO - BELOTUR. Relatório de Atividades 2014. Belo Horizonte, 2014. 58 p.

EMPRESA MUNICIPAL DE TURISMO - BELOTUR. Relatório do Carnaval de BH 2015. Belo Horizonte, 2015. 39 p.

FERREIRA, F. O livro de ouro do Carnaval brasileiro. 1 ed. Rio de Janeiro: Ediouro, 2004.421 p.

FIGUEIREDO, A. A.; MAYER, V.F.; A Imagem dos Destinos Turísticos: a cidade de São Paulo sob o olhar de jovens do Rio de Janeiro. Revista Turismo em Análise, São Paulo, v. 21, n.3, Revista Turismo - Visão e Ação - EletrônicA, Vol. 18 - N. 2 - MAI. - Ago. 2016 
p. 445-469, dez. 2010.

GETZ, D. Special events: Defining the product. Tourism management, v. 10, n. 2, p. 125137, 1989.

HELDER, R. R. Como fazer análise documental. Porto, Universidade de Algarve, 2006.

HOLANDA, T. Ocupando espaços. Estado de Minas. Belo Horizonte, 14 fev. 2013. Caderno Gerais. p. 17.

JORNAL ESTADO DE MINAS. Mais atenção aos blocos. Belo Horizonte, p. 2-2. 19 fev. 2013.

KOTLER, P.; LEE, N. R. Marketing Social: Influenciando Comportamentos para o bem. 3. ed. Porto Alegre: Bookman, 2011. 454 p.

KOTLER, P.; LEE, N. Marketing no Setor Público: Um guia para um desempenho mais eficaz. Porto Alegre: Bookman, 2008. 350 p.

KOTLER, P. et al. Marketing de lugares: como conquistar crescimento de longo prazo na América Latina e no Caribe. Pearson Prentice Hall, 2006.

LIRA, S. Com campanha de conscientização do uso de água, Belotur lança oficialmente o Carnaval de BH. Hoje em Dia. Belo Horizonte. 30 jan. 2015

MINCIOTTI, S. A.; SILVA. A.; Marketing de localidades: uma abordagem ampliada sobre o desenvolvimento da cidade ou região. Revista Turismo Visão e Ação, Balneário Camboriú, v. 13, n.3, p. 329-346, set - dez. 2010.

MARZANO, F.; WERNECK, G.; FONSECA, J. Então até o ano que vem. Estado de Minas. Belo Horizonte, 18 fev. 2015. Caderno especial, p. 8.

MUZZI, L. Musicalidade domina nomes por trás dos blocos de rua de BH. O Tempo. Belo Horizonte, 08 fev. 2015. Disponível em: <http://www.otempo.com.br/cmlink/hotsites/ carnaval-2015/musicalidade-domina-nomes-por-tr\%C3\%A1s-dos-blocos-de-rua-de-bh1.990680>. Acesso em 27 mar. 2015.

OLIVEIRA, T. BH terá pacotes turísticos no carnaval deste ano. Hoje em Dia. Belo Horizonte. Caderno Horizonte p. 24.09 jan. 2015.

OLIVEIRA, J.; KREFER, S. Lições de um Carnaval Renascido: Multidão nas ruas mostra que é preciso mais estrutura para a folia. Estado de Minas. Belo Horizonte, p. 17-17. 14 fev. 2013.

OLIVEIRA, J.; WERNECK, G.; FURBINO, Z. Os dois lados da mesma folia: Lições da Folia. Estado de Minas. Belo Horizonte, p. 17-18. 06 mar. 2014. 
PELEGRINI, L. Alalaô. Folha de São Paulo. São Paulo, 30 jan. 2015.

PEREIRA FILHO, H. F. Glórias, conquistas, perdas e disputas: as muitas máscaras dos carnavais de rua em Belo Horizonte (1899-1936). 2006. 221 f. Dissertação (Mestrado) - Curso de Pós Graduação em História, Faculdade de Filosofia e Ciências Humanas, Universidade Federal de Minas Gerais, Belo Horizonte, 2006.

R7. Ministério Público decide que Carnaval em Santa Tereza dever terminar às 19 horas. Notícias. Disponível em: <http://entretenimento.r7.com/carnaval-2015/ministerio-publico-decide-quecarnaval-no-santa-tereza-deve-terminar-as-19h-05022015>. Acesso em 6 maio. 2015.

ROCHA, M.; Política e Carnaval. O Tempo. Belo Horizonte, p. 2. Primeiro Caderno. 06. Mar 2014.

SANCHEZ, F. Políticas Urbanas em Renovação: Uma Leitura Crítica dos Modelos Emergentes. Revista Brasileira de Estudos Urbanos e Regionais, São Paulo, n.1, p.115-132, maio 1999.

SANTOS, F. B. P. Carnaval e Administração Pública: como os governos locais têm lidado com essa relação. In: ENCONTRO NACIONAL ADMINISTRAÇÃO PÚBLICA E GOVERNANÇA (EnAPG). Anais... Salvador, Bahia, 2008.

TEIXEIRA, C. A. Pernas para o ar que ninguém é de ferro!!! Lembranças da Banda. Belo Horizonte: Historiarte, 2005. 72p.

TRIGUEIRO, O. M. A espetacularização das culturas populares ou produtos culturais folkmidiáticos. 2005. Disponível em: <http://bocc.ubi.pt/pag/trigueiro-osvaldoespetacularizacao-culturas-populares.html>. Acesso em: 12 nov. 2014.

VERGARA, S. C. Projetos e Relatórios de Pesquisa em Administração. 10. ed. São Paulo: Atlas, 2009. 90 p.

WERKEMA, M. Presidente da Belotur. Entrevista para o Jornal Estado de Minas.18 fev. 2015. p.16

XAVIER, L. M. S. Qualidade dos serviços ambulatoriais de saúde: um estudo no município de Acaiaca/MG. 2013. 95 f. Dissertação (Mestrado em Administração). Faculdade Novos Horizontes, Belo Horizonte. 2013.

ZUCCO, F. D.; REIS, C. Comunicação Integrada de Marketing dm Eventos Turísticos: um estudo da Oktoberfest de Blumenau- Sc. Revista Brasileira de Marketing, São Paulo, v. 9, n. 3, p.127-143, 2010. 